\title{
Expression of The Fab Enzymes (Fab I And Fab Z) \\ From Plasmodium Falciparum After Exposure To Artemisia Afra Plant Extracts And Drugs Screening
}

Ndeye Fatou Kane ( $\nabla$ nfatoukane86@live.fr)

Pan African University Institute for Basic siences, Technology and Inovation/ JKUAT (PAUISTI-JKUAT) https://orcid.org/0000-0002-3846-9109

Mutinda Cleophas Kyama

Jomo Kenyatta University of Agriculture and Technology

Joseph Kangethe Nganga

Jomo Kenyatta University of Agriculture and Technology

Ahmed Hassanali

Kenyatta University

Mouhamadou Diallo

Université Cheikh Anta Diop de Dakar: Universite Cheikh Anta Diop de Dakar

Francis Kimani

KEMRI: Kenya Medical Research Institute

Research

Keywords: Artemisia afra, Fab I , FabZ, drugs screening, gene expression

Posted Date: June 29th, 2021

DOI: https://doi.org/10.21203/rs.3.rs-647186/v1

License: (c) (1) This work is licensed under a Creative Commons Attribution 4.0 International License.

Read Full License 


\section{Abstract}

Background:

The emergence and spread of drug resistance of the malaria parasite to the main treatment emphasis the need to develop new antimalarial drugs. In this context, the fatty acid biosynthesis (FAS_II) pathway of the malaria parasite is one of the ideal target due to its crucial role in parasite survival.

Method:

We report in this study the expression and the affinity binding of two Fab enzymes (Fabl and FabZ) after exposure of the parasite using different extracts of the Artemisia afra and after a virtual screening with the different plant compounds. Two differents strains of Plasmodium falciparum was used: W2 (CQ_resistant) and D6 (CQ_sensitive) with a parasiteamia of 4\%. The parasites were exposed during 2 days to different Artemisia afra extracts. Gene expression was done to determine the level of expression of the fab enzymes after treatments. A GCMS was run to determine the different compounds of the plant extracts following by a virtual screening between the fab enzymes and the active compounds using Pyrex.

Result:

The results showed different expression patterns of the Fab enzymes. Fabl was downregulated in the W2 and D6 strains by the ethanolic extract in a higher rate for W2. Hexane and DCM extracts increased the production of Fabl respectively in W2 and D6 strains. A different expression pattern was observed for Fab Z. The expression of FabZ in the W2 strain were all upregulated. The enzyme was downregulated only in the D6 strain when exposed to the ethanolic and hexane extracts of the plant. After virtual screening, a lot of compounds were found to interact with the two fab enzymes. Hits compounds for Fabl and FabZ with high biding energy were detected. 11alpha-Hydroxyprogesterone and Aspidospermidin-17-ol were found to have high binding energy with Fabl respectively $(-10.7 \mathrm{kcal} / \mathrm{mol} ;-10.2 \mathrm{kcal} / \mathrm{mol})$. Fab Z was having also a high affinity with the two following hits compounds: 11alpha-Hydroxyprogesterone $(-10 \mathrm{kcal} / \mathrm{mol})$ and Thiourea $(-8.4 \mathrm{Kcal} / \mathrm{mol})$.

Conclusion:

The study showed that Artemisia afra is a big source of antimalarial drugs, and could act not only as a curative but also as prophylactic due to its effects on the Fab enzymes.

\section{Introduction}

Malaria is still a big concern into the Africa health system due to its high number of death yearly. Africa is the most affected where more than $90 \%$ of the death occur in those sub-Saharan countries. Today we are facing a big challenge concerning the spread of the resistance to main drugs wildly spread in South East Asia a treat that can drive into Africa. New indigenous gene mutations of the Plasmodium falciparum 
parasite were discovered in Rwanda in 2020. The mutation is about a new indigenous lineage concerning the $p f k e l c h 13 \mathrm{R} 561 \mathrm{H}$ that can drive Artemisinin resistance (1). This raises need for developing new drugs that can overcome that resistance. Researchers are getting more and more focused on the use of medicinal plants as a polytherapy that works better into overcoming parasite resistance. Artemisia afra is one of those promising medicinal plant with a high antimalarial effect and not toxic in high dosage. This plant is growing wildly from cape to the Eastern part of Africa, and where used for decades by traditional healers it is one of the best known medicinal plant. The list of uses covers a wide range of ailments from coughs, colds, fever, loss of appetite, colic, headache, earache, intestinal worms to malaria $(2,3,4)$. In this project different strains of malaria parasite W2 (CQ resistant) and D6 (CQ sensitive) were exposed to different extracts of Artemisia afra collected from Burundi, to monitor the expression level of different genes Fab I and Fab Z that belong to the Fab enzymes, type II pathway implyed in the fatty acid biosynthesis of the malaria's parasite. Those Fab enzymes are crucial for the parasites survival and spreading mostly during the liver stage, and are targets for the development of new drugs candidate. Studying their expression when exposing the parasites to the plant extracts can bring a lot of informations about using those genes as target for new drugs.

\section{Materials And Methods}

\section{Artemisia afra extraction:}

\subsection{Plant preparation:}

Burundi at Rumonge South Burundi. The leaves were harvested before blooming and dried under shade before being sent to Nairobi in paper bags, then kept at room temperature until extraction.

\subsection{Extraction Process}

Samples of dried and powdered aerial part of $A$. afra weighing each $125 \mathrm{gm}$ were extracted with $600 \mathrm{~mL}$ of Ethanol (100\%), Hexane (85\%), DCM $(99.9 \%)$ and in water $(800 \mathrm{~mL})$ in a flat bottomed flask and mixed on an orbital shaker. After gentle maceration for 48 hours, the extracts were filtered through Whatman filter paper $n^{\circ} 1$. The filtrate was concentrated under reduced pressure using rotary evaporator at $20 \mathrm{rpm}$ and $40^{\circ} \mathrm{C}$ bath temperature. Finally, concentrated extracts were collected in vials and placed on a water bath at $40^{\circ} \mathrm{C}$ to evaporate the remaining solvents and stored at room temperature for complete dryness.

\section{Gene expression study for Fab_Z and Fab_I from P. falciparum after exposition of the parasites to the crude extracts.}

\subsection{Culture preparation and incubation}

Cultures of Plasmodium falciparum (W2 and D6) with a parasitaemia of $4 \%$ were incubated with Artemisia afra extracts collected from Burundi, e.g.: Burundi ethanolic, hexane and dichloromethane extract to run an inhibition test. 
Artemisia afra solution was made for all the extracts. $100 \mathrm{mg}$ of extracts were dissolved in 200ul of DMS; double distilled water was used to dilute the extracts. $20 \mathrm{ml}$ of double distilled water was added to the final concentration of $5 \mathrm{ug} / \mathrm{ul}$; then the solution was sterilized by filtering it through a microfilter of $0.45 \mathrm{um}$ pore size.

- $6 \mathrm{ml}$ of W2 cultures were incubated with $666 \mathrm{ul}$ of $A$. afra extracts (DCM,ETOH.and Hexane plant extracts) at a final concentration of $0.5 \mu \mathrm{g} / \mu \mathrm{l}$

- $6 \mathrm{ml}$ of W2 culture as negative control incubated with 666ul CMS with DCMS (final DMSO concentration was $0.1 \%$ )

- $6 \mathrm{ml}$ of D6 cultures were incubated with 666ul of $A$. afra extracts (DCM, EtoH,and Hexane plant extracts) at a final concentration of $0.5 \mu \mathrm{g} / \mu \mathrm{l}$

$6 \mathrm{ml}$ of D6 culture as negative control were incubated with 666ul CMS and DMSO (final concentration of DMSO was $0.1 \%$ ).

The parasites were then kept for 2 days in the incubation room. After the inhibition test was done, the parasite were kept at $-80^{\circ} \mathrm{C}$. The samples were used later for RNA extraction to run gene expression of FAB_Z and FAB_I in each sample.

\subsection{RNA extraction:}

After the inhibition test was done, the total RNA for all samples (W2 and D6) was extracted by following the method of trizol reagent Invitrogen Company (http://tools.thermofisher.com/content/sfs/manuals/trizol_reagent.pdf).

The parasites were thawed in ice, the whole blood was centrifuged, and the supernatant was discarded. The pellet was lysed using $1 \mathrm{ml} \mathrm{Trizol,} \mathrm{then} \mathrm{Incubated} \mathrm{at} 37^{\circ} \mathrm{C}$ for 5 min to ensure the complete deproteinization of nucleic acids. 200ul of Chloroform was added, the tube was shaken vigorously by hand followed or using a vortex then centrifuged during $15 \mathrm{~min}$ at $12,000 \mathrm{~g}$ at $4^{\circ} \mathrm{C}$. The upper aqueous phase was carefully removed and placed in a new tube. Isopropanol was added (to precipitate the RNA) then mixed and centrifuged at $12,000 \mathrm{~g}$ at $4^{\circ} \mathrm{C}$ during $15 \mathrm{mn}$. The supernatant was discarded and the pellet suspended with $1 \mathrm{ml}$ of $75 \%$ ethanol then vortex briefly and centrifuge for $10 \mathrm{mn}$ at $7,500 \mathrm{~g} 4^{\circ} \mathrm{C}$. The supernatant was discarded and the pellet air dried for $10 \mathrm{mn}$. The RNA was resuspended with $40 \mathrm{ul}$ of RNAs-free water and incubated in a heat block for 10 minutes at $60^{\circ} \mathrm{C}$. The quantity and the quality of the RNA was determined respectively using Nano_Drop. The purity of the RNA sample was defined by the A260/A280 ratio. A ratio between 1.8 and 2.1 was indicative of highly purified RNA. The concentration of the extracted RNA was determined using the following equation:

RNA concentration $(\mu \mathrm{g} / \mu \mathrm{l})=(\mathrm{A} 260 * 40 * \mathrm{D}) / 1,000$ where $D=$ dilution factor

\section{3 cDNA synthesis}


The RNA samples were normalized by adding RNA free water to get a concentration of 50ug/ul of RNA for all samples; then the RNA was converted into cDNA by reverse transcription (RT). The oligo (DTs) primers were used for the reverse transcription. CDNA synthesis kit from Solis BioDyne was used for the reaction. The samples were incubated in PCR machine at $50^{\circ} \mathrm{C}$ during $45 \mathrm{mn}$ to allow the reverse transcription reaction to take place and to be complete, then in $85^{\circ} \mathrm{C}$ during $5 \mathrm{~min}$ to inactivate the enzyme and stop the reaction. The cDNA samples were then kept at $-20^{\circ} \mathrm{C}$ awaiting further analysis.

\subsection{FAB_Z FAB_I primers}

Primers for FAB_Z and Fab_I were created using Prime 3 (http://bioinfo.ut.ee/primer3-0.4.0/) and ordered online. The primers were designed to avoid hairpins and self-annealing with a GC content around $40 \%-$ $50 \%$ and an annealing temperature of $60^{\circ} \mathrm{C}$.

A stock solution of $100 \mathrm{uM}$ was prepared for each primers using PCR water buffer. 10ul from the stock solution was added to $90 \mathrm{ul}$ of PCR water to prepare a working solution of $10 \mathrm{uM}$.

- FAB_Z primer

OLIGO start len tm gc\% any_th 3'_th hairpin seq

LEFT PRIMER 5112058.9350 .000 .000 .000 .00 TTTGCTGGAGTGGATGGAGT

RIGHT PRIMER 68724 59.91 41.67 0.00 0.00 0.00 CGATAAGGCAAACGTCATTTCTGA

Product size: $177 \mathrm{bp}$

- FAB_I primer

OLIGO start len tm gc\% any_th 3'_th hairpin seq

LEFT PRIMER 3332260.3650 .000 .000 .000 .00 CGGGTGGGGTATTGCTAAAGAA

RIGHT PRIMER 5102059.3150 .001 .610 .000 .00 AGAAGCGTCAAAGGGTAGCA

PRODUCT SIZE: $178 \mathrm{bp}$

\subsection{Conventional PCR for FAB_I and FAB_Z}

The designed primers were tested during the conventional PCR, and their parameters set up. 5x FIREpol Master Mix ready to load with syber green dye was used for the conventional PCR. 4ul of a master mix containing DNA polymerase, $5 x$ reaction buffer, $12.5 \mathrm{mM} \mathrm{Mgcl}_{2}, 1 \mathrm{mM} \mathrm{dNTPs}$, blue and yellow dye added into labelled PCR tubes $1 u$ l of primers solutions were added cDNA samples were thawed and $2 u$ were added in each PCR tubes and topped up with water till 20 ul of the final volume. The sample was placed into the PCR thermocycler, and man run was set with different parameters until we find the right one that works better. The following amplification program was finally used for the two primers (FAB_Z and 
FAB_I): Initial denaturation at $95^{\circ} \mathrm{C}$ for $5 \mathrm{~min}$ and then 40 cycles of denaturation at $95^{\circ} \mathrm{C}$ for $1 \mathrm{~min}$, annealing $60^{\circ} \mathrm{C}$ for $1 \mathrm{~min}$, extension $72^{\circ} \mathrm{C}$ for $1 \mathrm{~min}$, followed by the final extension at $72^{\circ} \mathrm{C}$ for $10 \mathrm{~min}$, and then held at $4^{\circ} \mathrm{C}$. After gel electrophoresis was made to make sure that the primers got correctly amplified with those parameters set up.

\subsection{Housekeeping gene for $P$. falciparum}

To run gene expression of Fab enzymes: Fab_Z (Beta-hydroxyacyl-Acyl-carrier Protein Dehydratase) and Fab_I (Enoyl Acyl-Carrier-Protein Reductase) we needed a housekeeping gene as a reference which is necessary to calculate the expression level of the others genes during real-time PCR. In our study, Actin was chosen as the housekeeping gene for Plasmodium falciparum. Primers were made to amplify the actin gene during real-time PCR. Prime 3 was used to make the primers and parameters were set to fit the same parameters than for Fab_z and Fab_l.

- Actin Primers:

OLIGO start len tm gc\% any_th 3'_th hairpin seq

FORWARD PRIMER 8132059.8950 .000 .610 .00 0.00 AGCAGCAGGAATCCACACAA

REVERSE PRIMER 9762060.1150 .00 0.00 0.00 0.00 TGGTTGATGGTGCAAGGGTT

SEQUENCE SIZE: 1131

PRODUCT SIZE: 164

A conventional PCR was run first to test the primers chosen for actin as amplified. The following parameters were used: Initial denaturation at $95^{\circ} \mathrm{C}$ for $5 \mathrm{~min}$ and then 40 cycles of denaturation at $95^{\circ} \mathrm{C}$ for $1 \mathrm{~min}$, annealing $60^{\circ} \mathrm{C}$ for $1 \mathrm{~min}$, extension $72^{\circ} \mathrm{C}$ for $1 \mathrm{~min}$, followed by the final extension at $72^{\circ} \mathrm{C}$ for $10 \mathrm{~min}$, and then held at $4^{\circ} \mathrm{C}$. After gel electrophoresis was made to make sure that the primers got correctly amplify

\subsection{Gel electrophoresis for PCR products}

After running the conventional PCR for the genes and the housekeeping gene, a gel was prepared for the PCR product. Agarose gel (2\%) in 2x TBE buffer was prepared. Ethidium bromide was included in the gel. Eight $\mu$ of each amplification reaction was loaded onto the gel. A molecular weight ladder was included and run at for $40 \mathrm{~min}$. The gel visualized on UV trans-illuminator and photograph gel. The remaining of the $20 \mu \mathrm{l}$ of the PCR product stored at $-20^{\circ} \mathrm{C}$.

\subsection{Real-time PCR}

After a success amplification for all the genes (Fab_I and Fab_Z) and the housekeeping gene (Actin) a Real-time PCR was run to study the expression of the genes Fab_I and Fab_Z when exposed to our active 
extracts Artemisia afra. 5x HOT FIREPol EvaGreen qPCR mix plus (No Rox) from Solis BioDyne was used for the quantitative real-time PCR. The qPCR master mix composition was: Hot FIREpol DNA polymerase, $5 x$ Evagreen qPCR buffer, $12.5 \mathrm{mM} \mathrm{Mgcl}_{2}$, dNTPs, Evagreen dye, No ROX dye. 96 wells plate for real-time PCR were used to set the reaction (Fig. 3.1). In each well $10 \mu$ of total volume solution were prepared each containing $2 \mu \mathrm{l}$ of master mix for qPCR, $0.5 \mu \mathrm{l}$ for the reverse primers, $0.5 \mu \mathrm{l}$ for the forward primers, $2 u l$ for $\mathrm{CDNA}$ and $5 \mu \mathrm{l}$ of water. Each sample was tested in triplicate. LightCycler 96 software was used to set the parameters for Real-time qPCR and to visualize the results

\section{Virtual screening with Artemisia afra compounds found during GCMS and the Fab enzymes}

\subsection{Gas Chromatography Mass Spectrometry (GCMS) Analysis of Artemisia afra extracts}

Artemisia afra from Burundi was collected and extracted with three solvents: Dichloromethane, Ethanol, and Hexane. The extracts were dried using rotary evaporator and kept in the oven at $37 \mathrm{C}$ until complete evaporation of the solvents. Pure artemisinin crystal was used as a standard to test any presence of the compound in Artemisia afra extracts.

\subsubsection{Sample Preparation}

Samples were dissolved and diluted in suitable organic solvents i.e. dichloromethane and ethanol extracts were dissolved in methanol solvent, while hexane extract was dissolved in hexane solvent) and passed through carbon black to remove waxes and chlorophylls. The samples were then filtered through $0.45 \mu \mathrm{m}$ PTFE filters then transferred to sample vials for GCMS analysis.

\subsubsection{GCMS Method}

A Shimadzu QP 2010-SE GCMS coupled to an autosampler was used for the analysis. Ultrapure He $(99.999 \%)$ was used as the carrier gas at a flow rate of $1 \mathrm{ml} /$ minute. A BPX5 non-polar capillary column, $30 \mathrm{~m} ; 0.25 \mathrm{~mm}$ ID; $0.25 \mu \mathrm{m}$ film thickness, was used for separation. The GC was programmed as follows: $60{ }^{\circ} \mathrm{C} ; 10{ }^{\circ} \mathrm{C} / \mathrm{min}$ to $250{ }^{\circ} \mathrm{C}$ (10 minutes). Total run-time was 30 minutes. Only $1 \mu \mathrm{L}$ of the sample was injected. The injection was done in split mode, 10:1. Injection was done at $200^{\circ} \mathrm{C}$. The interface temperature was set at $250^{\circ} \mathrm{C}$. The El ion source was set at $200^{\circ} \mathrm{C}$. Mass analysis was done in full scan mode, $50-550 \mathrm{~m} / \mathrm{z}$. A solvent delay time of 2 minutes was used.

\subsection{Drug screening with PyRx}

After GCMS a library of compounds was prepared based on the GCMS results of Artemisia afra extracts from Burundi. The library was screened against two macromolecules (FAB_I FAB_Z) using Autodock Vina in PyRx 0.8 version [5]. PyRx is a Virtual Screening software for Computational Drug Discovery that can be used to screen libraries of compounds against potential drug targets. The software is open access and is available online at http://pyrx.sourceforge.net

\subsubsection{Preparation of the library of small molecules}


The 3D structures of all the compounds from GCMS were searched from three chemical structure database and downloaded. Three databases were used: ChemSpider (http://www.chemspider.com/), PubChem from NCBI (https://pubchem.ncbi.nlm.nih.gov/search/), and ChEMBL (https://www.ebi.ac.uk/chembl/) from the European Bioinformatics Institute (EBI). The small molecules (Compounds) were downloaded and visualize with Pymol then save in the same file in PDB format.

\subsubsection{D structure of Plasmodium falciparum Fab enzymes: Fab Z and Fab I}

The 3D structure of the Fab enzymes: Fab_Z and Fab_I were downloaded from the RCSB protein database (PDB), (https://www.rcsb.org/). Fab_Z (PDB entry: 3AZA), [6]; Fab_I (PDB entry: 3LT0), [7]. The macromolecules were crystallized with their ligands. The macromolecules were open in txt format with notepad then all the ligands were removed to free the interaction sites.

\subsubsection{Virtual screening with PyRx: Protocol}

PyRx (Fig. 1) have the two virtual screening software Autodock 4.0 and Autodock vina. Autodock Vina was used during the drug screening because AutoDock Vina significantly improves the average accuracy of the binding mode predictions compared to AutoDock 4 and is faster (5).

\section{Results}

\section{Gene expression results}

\subsection{Gel electrophoresis for PCR product}

After parasite RNA extraction with trizol from the 8 samples, we got different concentration of RNA for each sample after measuring with a nanodrop. The concentration of RNA was normalized to get equal concentration for the 8 samples (experimentals and controls) before making the cDNA. A conventional PCR was then run to parameter the primers for the Fab enzyme genes and the housekeeping gene (Actine). A gel was run for the PCR product (Fig. 2).

The results showed that the primers had well amplified the Fab enzymes genes and also the housekeeping gene. Many parameters were set to get the best amplification. The amplification was optimum with these parameters: Initial denaturation at $95^{\circ} \mathrm{C}$ for $5 \mathrm{~min}$ and then 40 cycles of denaturation at $95^{\circ} \mathrm{C}$ for $1 \mathrm{~min}$, annealing $60^{\circ} \mathrm{C}$ for $1 \mathrm{~min}$, extension $72^{\circ} \mathrm{C}$ for $1 \mathrm{~min}$, followed by the final extension at $72^{\circ} \mathrm{C}$ for $10 \mathrm{~min}$, and then held at $4^{\circ} \mathrm{C}$.

\subsection{Real-time amplification}

The same parameter for the conventional PCR was reported to do the real-time PCR for the gene expression study. The target genes were well amplified as shown in Fig. 3

In blue colour, we have the amplification for the housekeeping gene (Actin), in yellow the amplification for Fabl and in red colour the amplification for FabZ, In grey the amplification of the negative control and for 
the empty wells (that are drawn down of the picture). Actin has started first to be amplify following by Fabl then by FabZ. Actin was well amplified and has the best fluorescent curve till 5.7 then followed by Fab I that was also well amplified with a fluorescent curve till 5.7 then for FabZ was also well amplified with a fluorescent curve of 4.8 , but the amplification was less compared to the other genes.

\subsection{Gene expression for Fab I after exposition of the parasites to A. afra extracts}

The fold change expression of Fabl and FabZ was calculated from the Ct (cycle threshold is defined as the number of cycles required for the fluorescent signal to cross the threshold) values generated during the real-time PCR, and the result is showed in Table 1 and 2 The fold change for the untreated sample is 1 , for the treated samples when the fold change is greater than 1 it means that the targeted gene is upregulated and when it is lower than 1 it means that the targeted gene is downregulated. The Fab I gene from W2 strain of $P$. falciparum was upregulated with the hexane extract and downregulated by the ethanolic and dichloromethane extracts of the plant. In the second train for D6, we have a different path, Fabl is upregulated by DCM extract and downregulated by hexane and ethanolic extracts. In the two strains, Fabl appeared to be downregulated by the ethanolic extract of Artemisia afra (see Table 1).

Table 1

Fold change expression for Fabl after treatment with $A$. afra extracts

\begin{tabular}{|lll|}
\hline $\begin{array}{l}\text { EXTRACTS } \\
\text { ( } \text {. } \text { afra })\end{array}$ & Fold difference & Fold difference \\
\hline Untreated & 1 & D6 \\
\hline Hexane & $\mathbf{1 . 4 6}$ & 1 \\
\hline EToH & 0.34 & 0.47 \\
\hline DCM & 0.74 & 0.37 \\
\hline
\end{tabular}

The logarithm 10 of the fold change for Fabl in each treatment was calculated to make the histogram (Fig. 4). The histogram is centered in 0 which is the log 10 (fold change) of the untreated sample for D6 and W2. The up columns showed upregulation, and the down columns showed downregulation. Depending on the length of the column we can see the level of expression in both side when it is downregulated or when it is upregulated. In this figure Fab I is upregulated the hexane and DCM extract respectively in the W2 and D6 strain. However the upregulation appear to be 3 times higher in the D6 strain compared to W2 strain. Fab I downregulation is higher when exposed to the ethanolic extract in both strains.

\subsection{Gene expression for Fab Z after exposition to A. afra extracts}

For Fab Z in the W2 strain, the gene is upregulation when exposed to the three different extracts. For the D6 strain, the gene is also upregulated when exposed to the DCM extract but downregulated when 
exposed to the others extracts. Fab Z is upregulated by the DCM extract in the two strains of $P$. falciparum.

Table 2

Fold change expression for FabZ after treatment with $A$. afra extracts

\begin{tabular}{|lll|}
\hline $\begin{array}{l}\text { EXTRACTS } \\
(\boldsymbol{A} \text {. } \text { afra })\end{array}$ & Fold difference & Fold difference \\
\hline Untreated & 1 & D6 \\
\hline Hexane & $\mathbf{1 . 7}$ & 1 \\
\hline EToH & $\mathbf{2 . 4}$ & 0.3 \\
\hline DCM & $\mathbf{2 , 9}$ & 0.3 \\
\hline
\end{tabular}

The $\log 10$ of the fold difference was calculated (Fig. 5) and the histogram made to show the expression of FabZ ; this allowed a better view of the scheme of expression for FabZ depending on the extracts where they are exposed. The histogram is centered in 0 the up columns showed upregulation, and the down columns showed downregulation.

In this figure (Fig. 5) the downregulation of the enzyme Fab Z by the ethanolic and the hexane extract in the D6 strain appear to be almost at the same level.

\section{GCMS results}


Tableau 3: Main compounds detected by GCMS from dichloromethane extract, hexane and ethanolic extract of $A$. afra and result for GCMS for Artemisinin standard

\section{Standard/Extracts Name of the compounds}

\begin{tabular}{|c|c|c|c|c|}
\hline Standard/Extracts & Name of the compounds & Formula & $\begin{array}{l}\text { Retention } \\
\text { time (s) }\end{array}$ & $\begin{array}{l}\text { Area } \\
\%\end{array}$ \\
\hline & $\begin{array}{l}\text { Cyclodeca[b]furan-2(3H)-one, } \\
3 \mathrm{a}, 4,5,6,7,8,9,11 \mathrm{a} \text {-octahydro-3,6,10-trimethyl- }\end{array}$ & & 19.718 & 11.91 \\
\hline \multirow[t]{3}{*}{ Artemisinin } & Deoxyartemisinin & & 20.687 & 25.71 \\
\hline & 1,8-Diazabicyclo[5.4.0]undec-7-en-11-one & & 20.909 & 13.3 \\
\hline & $\begin{array}{l}\text { Bicyclo[4.1.0]heptane, 1-(3-oxo-4- } \\
\text { phenylthiobutyl)-2,2,6-trimethyl- }\end{array}$ & & 22.897 & 49.08 \\
\hline A afra DCM & 3,3,6-Trimethyl-1,4-heptadien-6-ol & & 5.964 & 1.11 \\
\hline \multirow[t]{17}{*}{ extract } & Eucalyptol & & 6.751 & 19.77 \\
\hline & 1,5-Heptadien-4-one, 3,3,6-trimethyl- & & 7.054 & 6.87 \\
\hline & $\begin{array}{l}\text { Cyclohexanol, 1-methyl-4-(1-methylethenyl)-, } \\
\text { cis- }\end{array}$ & & 7.377 & 0.68 \\
\hline & Linalool & & 7.76 & 1.06 \\
\hline & 5-Isopropyl-2-methylbicyclo[3.1.0]hexan-2-ol \# & & 7.909 & 1.79 \\
\hline & Camphor & & 8.794 & 1.29 \\
\hline & $\begin{array}{l}\text { Bicyclo[2.2.1]heptan-2-ol, 1,7,7-trimethyl-, (1S- } \\
\text { endo)- }\end{array}$ & & 9.176 & 31.87 \\
\hline & Hexane, 1,6-dimethoxy- & & 9.235 & 0.46 \\
\hline & $\begin{array}{l}\text { Cyclohexanol, 2-methyl-3-(1-methylethenyl)-, } \\
\text { (1.alpha.,2.alpha.,3.alpha.)- }\end{array}$ & & 10.013 & 0.81 \\
\hline & 1-Acetoxy-p-menth-3-one & & 10.472 & 0.65 \\
\hline & 1,7-Octadiene-3,6-diol, 2,6-dimethyl- & & 10.578 & 0.56 \\
\hline & Bornyl acetate & & 10.796 & 2.63 \\
\hline & $\begin{array}{l}\text { (1S,5S,6R)-6-Methyl-2-methylene-6-(4- } \\
\text { methylpent-3-en-1-yl)bicyclo[3.1.1]heptane }\end{array}$ & & 13.048 & 1.01 \\
\hline & $\begin{array}{l}\text { Methyl (1R,2R,8aS)-2-(methoxycarbonyl)-2- } \\
\text { hydroxy-5,5,8a-trimethyl-trans-decalin-1- } \\
\text { acetate }\end{array}$ & & 14.151 & 0.52 \\
\hline & $\begin{array}{l}\text { 2(4H)-Benzofuranone, 5,6,7,7a-tetrahydro- } \\
\text { 4,4,7a-trimethyl- }\end{array}$ & & 14.602 & 0.52 \\
\hline & 2,2,4-Trimethyl-1,3-pentanediol diisobutyrate & & 14.854 & 0.71 \\
\hline & Caryophyllene oxide & & 15.165 & 1.08 \\
\hline
\end{tabular}

Artemisinin

Cyclodeca[b]furan-2(3H)-one,

$3 a, 4,5,6,7,8,9,11$ a-octahydro-3,6,10-trimethyl- 
Tableau 3: Main compounds detected by GCMS from dichloromethane extract, hexane and ethanolic extract of $\boldsymbol{A}$. afra and result for GCMS for Artemisinin standard

\begin{tabular}{|c|c|c|c|}
\hline & .alpha.-Cadinol & 15.867 & 5.27 \\
\hline & $\begin{array}{l}\text { (1S,4aS,7R,8aS)-1,4a-Dimethyl-7-(prop-1-en-2- } \\
\text { yl)decahydronaphthalen-1-ol }\end{array}$ & 16.258 & 2.86 \\
\hline & Pulegone & 17.514 & 0.96 \\
\hline & 2-Pentadecanone, 6,10,14-trimethyl- & 17.837 & 1.64 \\
\hline & $6-\mathrm{C} 14 \mathrm{H} 26$ & 20.551 & 0.42 \\
\hline & Ethyl 9,12,15-octadecatrienoate & 20.636 & 0.52 \\
\hline & Phytol & 20.704 & 5.28 \\
\hline & Geranyl ethyl ether 2 & 21.142 & 1.99 \\
\hline & 11alpha-Hydroxyprogesterone & 21.325 & 2.31 \\
\hline & 11alpha-Hydroxyprogesterone & 22.075 & 3.77 \\
\hline & $\begin{array}{l}\text { 1-Aminocyclopentanecarboxylic acid, N-(but- } \\
\text { 3-yn-1-yloxycarbonyl)-, but-3-yn-1-yl ester }\end{array}$ & 22.97 & 1.59 \\
\hline A. afra Hexane & $\begin{array}{l}\text { Bicyclo[2.2.1]heptane, 2,2-dimethyl-3- } \\
\text { methylene-, (1S)- }\end{array}$ & 5.4 & 2.68 \\
\hline \multirow[t]{9}{*}{ extract } & Eucalyptol & 6.745 & 55.52 \\
\hline & 1,5-Heptadien-4-one, 3,3,6-trimethyl- & 7.048 & 24.19 \\
\hline & Undecane & 7.621 & 2.45 \\
\hline & Dodecane & 9.231 & 3.62 \\
\hline & $\begin{array}{l}\text { Acetic acid, 1,7,7-trimethyl-bicyclo[2.2.1]hept- } \\
\text { 2-yl ester }\end{array}$ & 10.783 & 3.72 \\
\hline & .alfa.-Copaene & 12.167 & 2.95 \\
\hline & Tetradecane & 12.221 & 1.24 \\
\hline & Caryophyllene & 12.87 & 2.42 \\
\hline & $\begin{array}{l}\text { 4a,8-Dimethyl-2-(prop-1-en-2- } \\
\text { yl)-1,2,3,4,4a,5,6,7-octahydronaphthalene }\end{array}$ & 13.764 & 1.21 \\
\hline A. afra Ethanolic & 3,3,6-Trimethyl-1,4-heptadien-6-ol & 5.967 & 0.45 \\
\hline \multirow[t]{3}{*}{ extract } & Eucalyptol & 6.75 & 5.58 \\
\hline & 1,5-Heptadien-4-one, 3,3,6-trimethyl- & 7.054 & 3.23 \\
\hline & 2,7-Dimethyl-2,6-octadien-4-ol & 7.417 & 1.01 \\
\hline
\end{tabular}




\section{Tableau 3: Main compounds detected by GCMS from dichloromethane extract, hexane and ethanolic}

extract of $A$. afra and result for GCMS for Artemisinin standard

\begin{tabular}{|c|c|c|}
\hline $\begin{array}{l}\text { Bicyclo[2.2.1]heptan-2-one, 1,7,7-trimethyl-, } \\
\text { (1S)- }\end{array}$ & 8.796 & 1.02 \\
\hline $\begin{array}{l}\text { Bicyclo[2.2.1]heptan-2-ol, 1,7,7-trimethyl-, (1S- } \\
\text { endo)- }\end{array}$ & 9.173 & 30.12 \\
\hline 3,7-Octadiene-2,6-diol, 2,6-dimethyl- & 9.227 & 0.69 \\
\hline 1,7-Octadiene-3,6-diol, 2,6-dimethyl- & 10.573 & 1.11 \\
\hline Bornyl acetate & 10.794 & 0.96 \\
\hline $\begin{array}{l}\text { 3-Cyclohexene-1-methanol, 2- } \\
\text { hydroxy-.alpha.,.alpha.,4-trimethyl- }\end{array}$ & 11.932 & 1.5 \\
\hline$(1 S, 2 S, 4 S)$-Trihydroxy-p-menthane & 13.964 & 1.99 \\
\hline 4-O-Methylmannose & 14.289 & 6.76 \\
\hline .alpha.-Cadinol & 15.863 & 1.73 \\
\hline .alpha.-Methyl mannofuranoside & 16.132 & 18.51 \\
\hline $\begin{array}{l}\text { (1S,4aS,7R,8aS)-1,4a-Dimethyl-7-(prop-1-en-2- } \\
\text { yl)decahydronaphthalen-1-ol }\end{array}$ & 16.253 & 2.06 \\
\hline Longifolenaldehyde & 17.907 & 3.05 \\
\hline Pentadecanoic acid & 19.154 & 0.75 \\
\hline Longifolenaldehyde & 19.276 & 1.56 \\
\hline Phytol & 20.703 & 1.67 \\
\hline Corymbolone & 21.316 & 3.57 \\
\hline $\begin{array}{l}\text { 5.beta.-Androstan-3.alpha.,11.alpha.,17.beta.- } \\
\text { triol }\end{array}$ & 22.07 & 1.58 \\
\hline $\begin{array}{l}\text { 2-((2R,4aR,8aS)-4a-Methyl-8- } \\
\text { methylenedecahydronaphthalen-2-yl)prop-2- } \\
\text { en-1-ol }\end{array}$ & 24.025 & 3.35 \\
\hline $\begin{array}{l}\text { 1H-1,3a-Ethanopentalen-5(4H)-one, 2,3- } \\
\text { dihydro- }\end{array}$ & 24.124 & 3.18 \\
\hline $\begin{array}{l}\text { Thiourea, 1-(adamantane-1-carbonyl)-3- } \\
\text { cyclohexyl- }\end{array}$ & 26.574 & 4.57 \\
\hline
\end{tabular}

After the GCMS of extracts of Artemisia afra from Burundi, the results in the table 3 showed that the ethanolic and dichloromethane extract had a high content of Bicyclo [2.2.1] heptan-2-ol, 1,7,7-trimethyl-, (1S-endo)-. The hexane extract had the same compound but at low amount compared to ethanolic and DCM extracts. The major compound in the hexane extract is Eucalyptol (Area 55.52) this compound is 
also found in DCM extract though at a lower amount (area 19.77) and also in ethanolic extract of $A$. afra (5.59). Hexane extract has fewer compounds compared to the others. Most of the compounds present in the ethanolic extract are also present in methanolic extract.

\section{Drug screening with PyRx:}

After GCMS of the ethanolic, hexane and dichloromethane extracts in total, 51 molecules were detected. The affinity of the molecules was tested against Fabl and FAB Z with vina. After drug screening, the binding energy for each molecule was determined and expressed in $\mathrm{Kcal} / \mathrm{mol}$ see Table 4 . The results showed that many compounds have a high affinity with the Fab enzymes. 
Artemisia afra compounds from GCMS and Docking energy with Fabl and FabZ

\section{Ligands}

Binding Energy Binding Energy

(Kcal/mol) (Fabl)

(Kcal/mol) (FabZ)

$(1 S, 2 S, 4 S)$-Trihydroxy-p-menthane

.alfa.-Copaene

.alpha.-Cadinol

.alpha.-Methyl_mannofuranoside

1_6-Dimethoxyhexane

1_7-Octadiene-3_6-diol_2_6-dimethyl-

1-Acetoxy-p-menth-3-one

1-Aminocyclopentanecarboxylic_acid_N-but-3-yn-1-

yloxycarbonyl-but-3-yn-1-yl_ester

1H-1,3a-Ethanopentalen-5(4H)-one_23-dihydro-

2-((2R,4aR,8aS)-4a-Methyl-8-

methylenedecahydronaphthalen-2-yl)prop-2-en-1-ol

2_2_4-Trimethyl-1_3-pentanediol_diisobutyrate

2_4H_-Benzofuranone_5_6_7_7a-tetrahydro-4_4_7atrimethyl-

2_7-Dimethyl-2_6-octadien-4-ol

2-Pentadecanone_6_10_14-trimethyl-

3_7-Octadiene-2_6-diol_2_6-dimethyl-

3-Cyclohexene-1-methanol__2-hydroxy-.alpha._.alpha._4trimethyl-

3-Isopropenyl-2-methylcyclohexanol

4a_8-Dimethyl-2-_prop-1-en-2-yl_-1,2,3,4,4a,5,6,7octahydronaphthalene

4-0-Methylmannose

5.beta.-Androstan-3.alpha.11.alpha.17.beta.-triol

6-C14H26_tetradecyne

Acetic_acid_1_7_7-trimethyl-bicyclo_2.2.1_hept-2yl_ester

Aspidospermidin-17-ol, 1-acetyl-19, 21-epoxy-15, 16dimethoxy
$-6.4$

$-6.1$

$-7.9$

$-7.1$

$-8.1$

$-7.4$

$-5.7$

$-5.3$

$-4.7$

$-4.9$

$-5.7$

$-6.6$

$-6.9$

$-6.9$

$-7.1$

$-4.9$

$-6.7$

$-6.5$

$-7.9$

$-6.1$

$-6.8$

$-6.6$

$-7.2$

$-6.2$

$-6.3$

$-6.6$

$-6.2$

$-5.5$

$-6.1$

$-5.2$

$-7.0$

$-5.8$

$-6.7$

$-6.9$

$-8.0$

$-5.6$

$-6.2$

$-4.8$

$-9.7$

$-7.6$

$-5.8$

$-6.3$

$-6.9$

$-5.9$

$-10.2$

$-7.6$ 


\begin{tabular}{|c|c|c|}
\hline Ligands & $\begin{array}{l}\text { Binding Energy } \\
\text { (Kcal/mol) (Fabl) }\end{array}$ & $\begin{array}{l}\text { Binding Energy } \\
\text { (Kcal/mol) (FabZ) }\end{array}$ \\
\hline Bergamotene & -7.5 & -8.0 \\
\hline Bicyclo_2.2.1_heptan-2-one_1_7_7-trimethyl-__1S_- & -6.3 & -6.7 \\
\hline Bicyclo_221_3d & -6.2 & -6.6 \\
\hline Borneol & -6.5 & -6.7 \\
\hline Bornyl_acetate & -6.9 & -5.9 \\
\hline Camphor & -6.3 & -6.7 \\
\hline Caryophyllene & -8.0 & -7.3 \\
\hline Caryophyllene_oxide & -8.3 & -7.0 \\
\hline Corymbolone & -8.6 & -7.3 \\
\hline Dodecane & -5.0 & -5.8 \\
\hline Ethyl_9_12_15-octadecatrienoate & -6.6 & -5.7 \\
\hline Eucalyptol & -6.4 & -5.9 \\
\hline Geranyl_ethyl_ether_2 & -5.6 & -5.9 \\
\hline Intermedeol_ & -7.8 & -7.0 \\
\hline Isoartemisia_ketone & -6.0 & -6.0 \\
\hline Linalool & -5.8 & -6.2 \\
\hline Longifolenaldehyde & -7.9 & -7.1 \\
\hline $\begin{array}{l}\text { Methyl_1R_2R_8aS_-2-_methoxycarbonyl_-2-hydroxy- } \\
\text { 5_5_8a-trimethyl-trans-decalin-1-acetate }\end{array}$ & -8.3 & -6.2 \\
\hline Pentadecanoic_acid & -5.6 & -4.8 \\
\hline Phytol & -6.4 & -7.2 \\
\hline 11alpha-Hydroxyprogesterone & -10.7 & -10.0 \\
\hline Pulegone & -7.8 & -5.7 \\
\hline Tetradecane & -5.2 & -5.5 \\
\hline Thiourea, 1-(adamantane-1-carbonyl)-3-cyclohexyl & -9.0 & -8.4 \\
\hline Thujanol & -6.3 & -6.3 \\
\hline trans-terpineol & -6.8 & -6.2 \\
\hline Undecane & -4.7 & -5.8 \\
\hline
\end{tabular}


The results showed some hit compounds for Fabl and FabZ with high biding energy. 11alphaHydroxyprogesterone have high binding energy with Fabl $(-10.7 \mathrm{kcal} / \mathrm{mol})$ and Fab Z $(-10 \mathrm{kcal} / \mathrm{mol})$. The second hit is Aspidospermidin, which also have a high binding energy with $\mathrm{Fabl}(10.2 \mathrm{kcal} / \mathrm{mol})$. The third is Thiourea,- which have a binding energy of $-9 \mathrm{kcal} / \mathrm{mol}$ for Fabl and $-8.4 \mathrm{kcal} / \mathrm{mol}$ for FabZ.

The binding site for Fab I with 11 alpha-hydroxyprogesterone (hit 1) and with Aspidospermidin (hit 2) were shown respectively in Fig. 4.14 and 4.15. The 3D structure of Fabl was download from PDB, and the active sites were determined before docking. After the virtual screening, the ligands were found to bind inside the active site and were in interaction with many residues in the active site (Fig. 6, 7).

Residue with hydrophobic interaction: Ile 369, Phe 368, Tyr 267, Tyr 277, Ala 312, Gly 313, Ser 215, Pro 314, Tyr 111, Leu 265, Ala 320, Ala 319 and hydrogen bound with Ser 317.

Residue with hydrophobic interaction: Tyr 277, Tyr 267, Ala 320, Gly 313, Leu 315, Tyr 111, Ser 317, Gly 110, Met 281, Ala217, Ala 319, lle 323, Lys 285, and Thr 266.

The binding site for FabZ with 11 alpha-hydroxyprogesterone (hit 1) and Thiourea,-(hit2) were shown respectively in Figs. 8 and 9. There is mostly hydrophobic interactions with the ligands, and also one hydrogen bind between Thiourea and the residue Tyr 100(G).

Residue with hydrophobic interaction: Tyr 100(I), Pro 101(K) 267, Tyr 100(H), Asn 131(K), Asn 131(I), Tyr 100 (L), Pro101(L), Pro 128 (K), Tyr 100(K), Asn 131(L) and Pro 128(L).

Residue with hydrophobic interaction: Phe 129(J), Pro 101(J), Pro 101(I), Tyr 100(I), Pro 128(I), Tyr 100 (I), Tyr 100(K), Asn $131(\mathrm{~L})$, Phe 129(J), Pro 128(J) and one hydrogen bond with Tyr 100(G).

\section{Discussion}

Inhibition test was run by incubating during 48hours the parasite cultures with $A$. afra extracts to study the expression level of the $P$. falciparum Fab enzymes (Fabl and Fab Z). The fab Enzymes play an important role in fatty acid synthesis pathway (FAS II). The prodigious proliferative capacity of malarial parasites necessitates access to an abundant source of fatty acids (FAs). These carboxylic acid-linked acyl chains are required for the production of lipid species that are essential for parasite membrane and lipid body biogenesis [8]. It has been shown that FAS II can be exploited for antimalarial drug discovery [9, 10]. In our results, FabZ (D6 strain) was found to be downregulated by the ethanolic and hexane extract of $A$. afra. Fab $Z$ is the primary dehydratase that participates in the elongation cycle of saturated as well as unsaturated fatty acid biosynthesis [11]. Downregulation of FabZ can lead to parasite death due to his crucial role in the fatty acid de novo biosynthesis. Fab I also play a crucial role during liver-stage of malaria infection [12]. A downregulation of Fab I can lead to a failure of the parasite to complete the liver stage by an inability to form intrahepatic merozoites that normally initiate blood-stage infection. The results showed a downregulation of Fab I by the ethanolic and the DCM extracts of Artemisia afra for the W2 strain. In the D6 strains the gene is also downregulated by the hexane and ethanolic extracts; this 
indicated that Artemisia afra could act as a drug with a prophylactic effect that can be able to stop the parasite in the earlier liver stage before the spread into the bloodstream.

\section{GCMS of Artemisia afra extracts}

GCMS was ran in all the three extracts: ethanolic; hexane and dichloromethane of Artemisia afra leaves from Burundi. 10 compounds were found in hexane extract; the major compound was Eucalyptol (55.5\%). Cineole or Eucalyptol has mucolytic, bronchodilating and anti-inflammatory properties and reduces the exacerbation rate in patients suffering from COPD (chronic obstructive pulmonary disease), as well as ameliorates symptoms in patients suffering from asthma and rhinosinusitis [13]. In the dichloromethane extract, 30 compounds were detected by GCMS, and the major compounds were Borneol (33.5\%) and Eucalyptol (21.9\%). Borneol is a common ingredient in many traditional Chinese herbal formula and has a wide range of uses, It aids the digestive system by stimulating the production of gastric juices; tones the heart and improves circulation; treats bronchitis, coughs, and colds; can relieve pain caused by rheumatic diseases and sprains; reduces swelling; relieves stress; and can be used as a tonic to promote relaxation and reduce exhaustion (http://acupuncturetoday.com/herbcentral/borneol.php). In the methanolic extract, the major compound was also Borneol (Bicyclo [2.2.1] heptan-2-ol, 1, 7, 7-trimethyl-, (1S-endo) (40.6\%). Majority of the compounds found in the ethanolic were also found in the

dichloromethane and some also in the hexane extract. The same major compound was found by Josphat et al. when analysing the essential oil from Artemisia afra by GCMS. The major constituents were 1, 8cineole (67.4\%), terpinen-4-ol (6.5\%) and borneol (5.1\%) [14]. The medicinal effect attributed to that plant can be because of the presence of all those active compounds. The first line against malaria is artemisinin and derivatives, which are extracted from Artemisia annua. Artemisinin was not detected in all three extracts of Artemisia afra, so this means that the antimalarial activity laid on the other actives compounds of that plant.

\section{Affinity binding with Fabl and FabZ}

A library was created based on the compounds found during GCMS and was screened against the two fab enzyme (Fab I and FabZ) to test virtualy their potential interactions using Autodock Vina with PyRx.

Autodock Vina is a docking software that aims to predict the ligand-protein complex structure interaction by exploring the conformational space of the ligands within the binding site of the protein. A scoring function is then utilized to approximate the free energy of binding between the protein and the ligand in each docking pose [15].

After the virtual screening all compounds were found to display a binding affinity that varies from high to low binding energies with the Fab enzymes, this may indicate that the all active compounds of Artemisia afra may play a significative rule by interacting with the $P$. falciparum Fab enzymes, which has a significant role in parasite survival during malaria infection. Comparison of the different binding energies for all molecules have shown up some dock hits. It was found that 11 alpha-Hydroxyprogesterone, Aspidospermidin-17-ol, 1-acetyl-19, 21-epoxy-15, 16-dimethoxy, and Thiourea, 1-(adamantane-1- 
carbonyl)-3-cyclohexyl were the efficient binders, with high binding energy. There is no literature about the pharmacological effects of Aspidospermidin- and Thiourea, 1-(adamantane-1-carbonyl)-3-cyclohexyl.

11alpha-Hydroxyprogesterone has recently been patented for the treatment of skin diseases, particularly psoriasis, it is an important pharmaceutical compound with anti-androgenic and blood-pressureregulating activity [16]. Those active compounds were also found to interact with most of the residue of the active side of Fab I. However, an in vitro test is necessary to confirm their antimalarial activity.

\section{Conclusion}

This study shows the high potential of the use of Artemisia afra as a source in the search of new antimalarial drugs. The FAS II pathway constitute a prime target for the development of prophylactic and curative drugs.

\section{Abbreviations}

GCMS: Gas Chromatography Mass Spectrometry

Ct: Cycle Threshold

PTFE: Polytetrafluoroethylene

KEMRI: Kenya Medical Research Institute
A: Actin
FZ: FabZ
Fl: Fabl
$\mathrm{N}:$ Negative Control
L: Ladder

\section{Declarations}

- Trial registration:

No applicable

- Ethical approval:

Ethical approval was provided by KEMRI (Kenya medical research institute).

- Fundings: 
This work was funded by PAU the Pan African University from Kenya.

- Consent for publication:

No applicable

- Acknowledgements:

Thanks for all the facilities provided by KEMRI/CBRD (Kenya Medical Research Institute/ Centre for Traditional Medicine and Drug Research). Thanks for Pierre Lutgen and lucile cornet vernet for Facilitate the obtention of that pant (Artemisia afra) through the organization: 'La Maison de L'artemisia'.

- Competing interest

The authors declare no competing interest.

- Availability of data and materials

Not applicable

- Authors contribution

Dr. Ndeye Fatou Kane: Corresponding author, Study Design, performs experimentations, Data analysis, and Article writing.

Dr. Mutinda Cleophas Kyama: Study Design, Data analysis,Writings

Dr. Joseph Kangethe Nganga : Study Design, Writings

Pr. Ahmed Hassanali: Study Design, writtings

Dr. Mouhamadou Diallo : Study Design, writing

Dr. Francis Kimani: Bring facilities to perform experimentations.

\section{References}

1. Uwimana, A., Legrand, E., Stokes, B.H. et al. Emergence and clonal expansion of in vitro artemisininresistant Plasmodium falciparum kelch13 R561H mutant parasites in Rwanda. Nat Med (2020). https://doi.org/10.1038/s41591-020-1005-2

2. Van Wyk B., Van Oudtshoorn B., Gericke N. Medicinal plants of South Africa, Briza Publications, Pretoria (1997)

3. Gathirwa J.W., Rukunga G.M., Njagi E.N.M., Omar S.A., Guantai A.N., Muthaura C.N., Mwitari P.G., Kimani C.W., Kirira P.G., Tolo F.M., Ndunda T.N., Ndiege I.O.In vitro anti-plasmodial and in vivo anti- 
malarial activity of some plants traditionally used for the treatment of malaria by the Meru community in KenyaJournal of Natural Medicine, 61 (2007), pp. 261-268

4. F.Van der Kooy ${ }^{\mathrm{a}}$ R.Verpoorte ${ }^{\mathrm{a}}$ J.J.Marion Meyer ${ }^{\mathrm{b}}$ Metabolomic quality control of claimed anti-malarial Artemisia afra herbal remedy and $A$. afra and $A$. annua plant extracts. South African Journal of Botany (2008) https://doi.org/10.1016/j.

5. Trott O., A. J. Olson, improving the speed and accuracy of docking with a new scoring function, efficient optimization and multithreading, Journal of Computational Chemistry AutoDock Vina: 2010, 455-461.

6. Maity et al., Structural basis for the functional and inhibitory mechanisms of $\beta$-hydroxyacyl-acyl carrier protein dehydratase (FabZ) of Plasmodium falciparum. J Struct Biol, 2011, 176, 238-249. PubMed id: 21843645

7. Maity K. et al., X-ray crystallographic analysis of the complexes of enoyl acyl carrier protein reductase of Plasmodium falciparum with triclosan variants to elucidate the importance of different functional groups in enzyme inhibition. lubmb Life, 2010, 62, 467-476. PubMed id: 20503440

8. Palacpac NM, Hiramine Y, Mi-ichi F, Torii M, Kita K, Hiramatsu R, Horii T, Mitamura T.; Developmentalstage-specific triacylglycerol biosynthesis, degradation and trafficking as lipid bodies in Plasmodium falciparum-infected erythrocytes. J Cell Sci. (2004), 117:1469-1480.

9. Waller, R. F.; Ralph, S. A.; Reed, M. B.; Su, V.; Douglas, J. D.; et al., 'A type Il pathway for fatty acid biosynthesis presents drug targets in Plasmodium falciparum.' Antimicrob. Agents Chemother. (2003),47,297-301

10. Perozzo, R.; Kuo, M.; Sidhu, A. b. S.; Valiyaveettil, J. T.; Bittman, R.; et al. 'Structural elucidation of the specificity of the antibacterial agent triclosan for malarial enoyl acyl carrier protein reductase.' J.Biol. Chem.( 2002), 277, 13106-13114

11. Kumar S. Sharma, Mili Kapoor T. N. C. Ramya, Sanjay Kumar, et al., Identification, Characterization, and Inhibition of Plasmodium falciparum _-Hydroxyacyl-Acyl Carrier Protein Dehydratase (FabZ), the journal of biological chemistry (2003), DOI 10.1074/jbc.M304283200

12. Min Yu,T. R. Santha Kumar, Louis J. Nkrumah et al., 'The Fatty Acid Biosynthesis Enzyme Fabl Plays a Key Role in the Development of Liver-Stage Malarial Parasites' Journal: Cell Host \& Microbe (2008)

13. Juergen Fischer, Uwe Dethlefsen. 'Efficacy of cineole in patients suffering from acute bronchitis: a placebo-controlled double-blind trial' Cough. ; 9: 25. Published online 2013 Nov 21. Doi: 10.1186/1745-9974-9-25

14. Josphat Mwangi, Kohath J. Achola, Kipruto A. Sinei, ' 'Essential Oil Constituents of Artemisia afra Willd' Journal of Essential Oil Research (1995) 7(1):97-99 DOl: 10.1080/10412905.1995.9698475.

15. Evanthia Lionta, George Spyrou, Demetrios K. Vassilatis and Zoe Cournia, , 'Structure-Based Virtual Screening for Drug Discovery: Principles, Applications and Recent Advances' Current Topics in Medicinal Chemistry (2014), 14, 1923-1938

16. Nguyen, Kim Thoa; Virus, Cornelia; Günnewich, Nils; Hannemann, Frank; Bernhardt, Rita. . "Changing the Regioselectivity of a P450 from C15 to C11 Hydroxylation of Progesterone". ChemBioChem 
(2012), 13 (8):1161-1166. doi:10.1002/cbic.201100811. ISSN 1439-4227

\section{Figures}

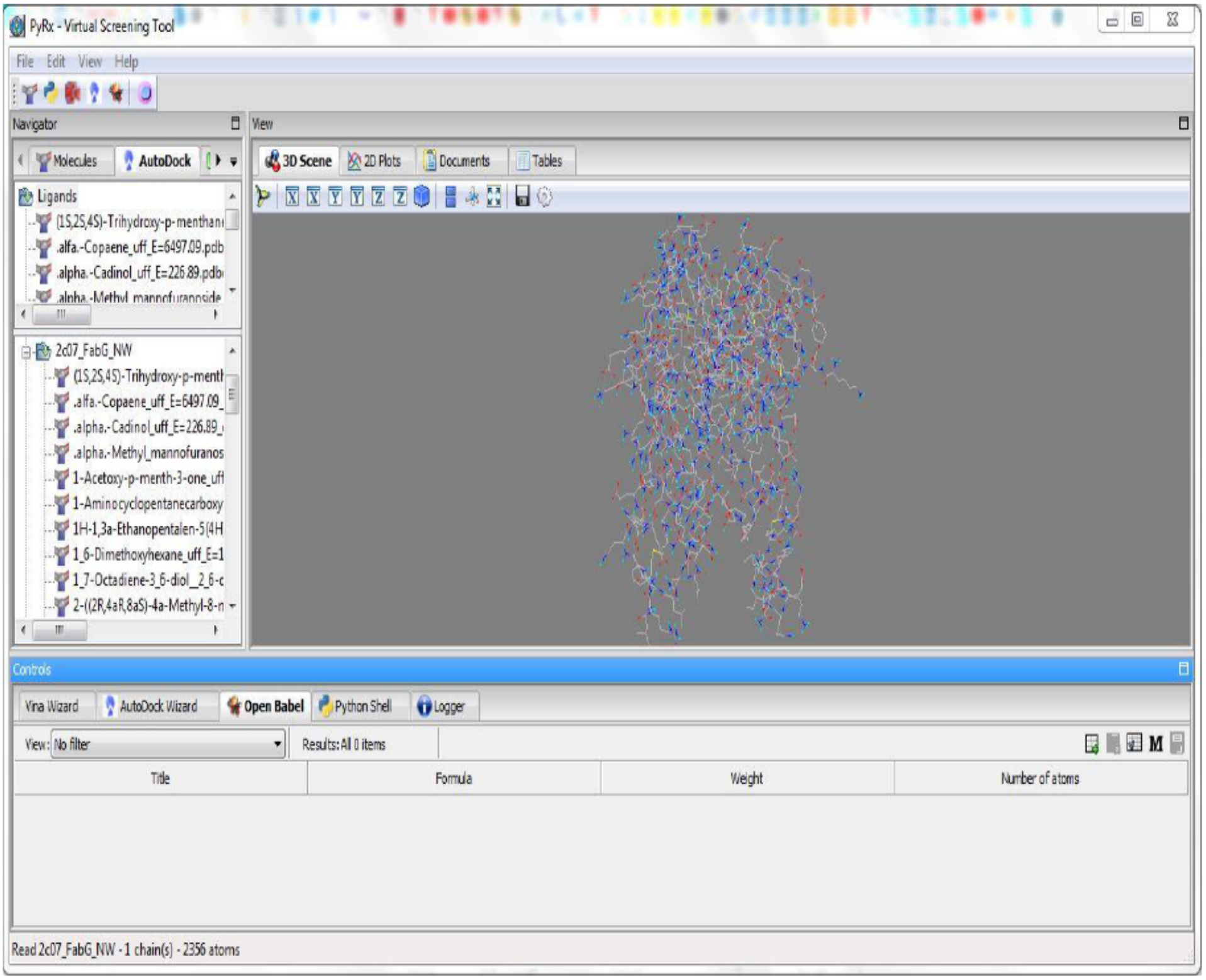

\section{Figure 1}

PyRx virtual screening interface. 

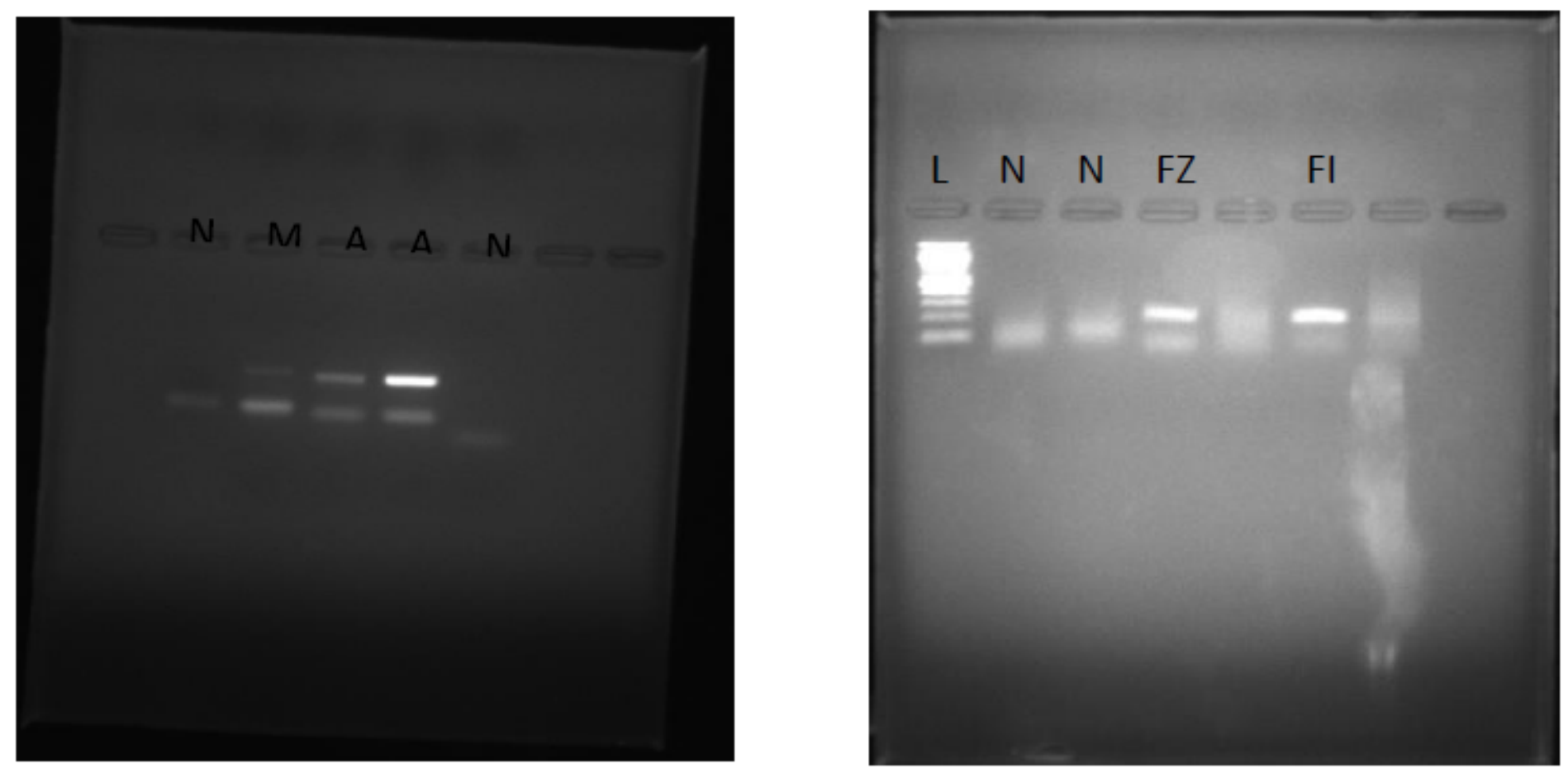

Figure 2

Gel electrophoresis of Actine Fabl and FabZ A: Actine FZ: FabZ FI: Fabl N: Negative control L: Ladder

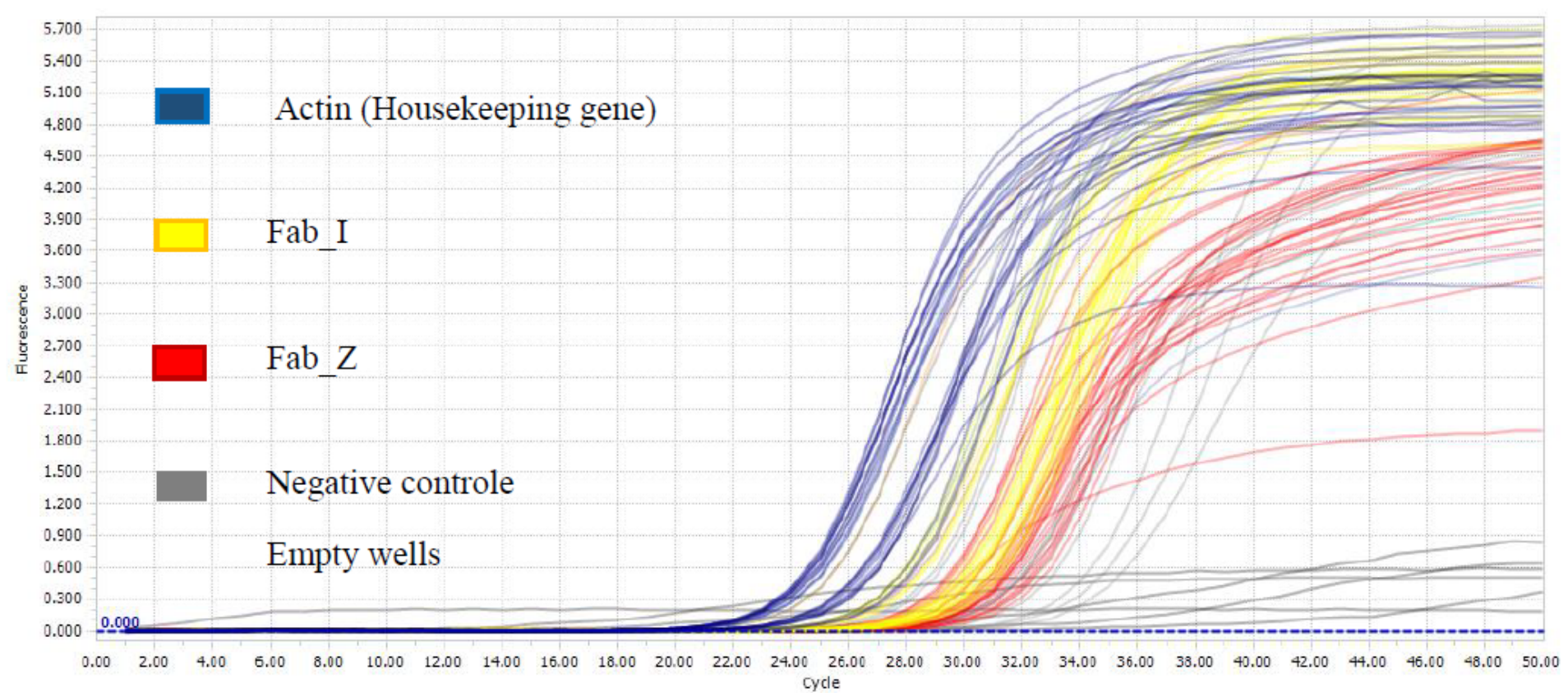

Figure 3

Amplification curves for Fabl, FabZ and Actin 


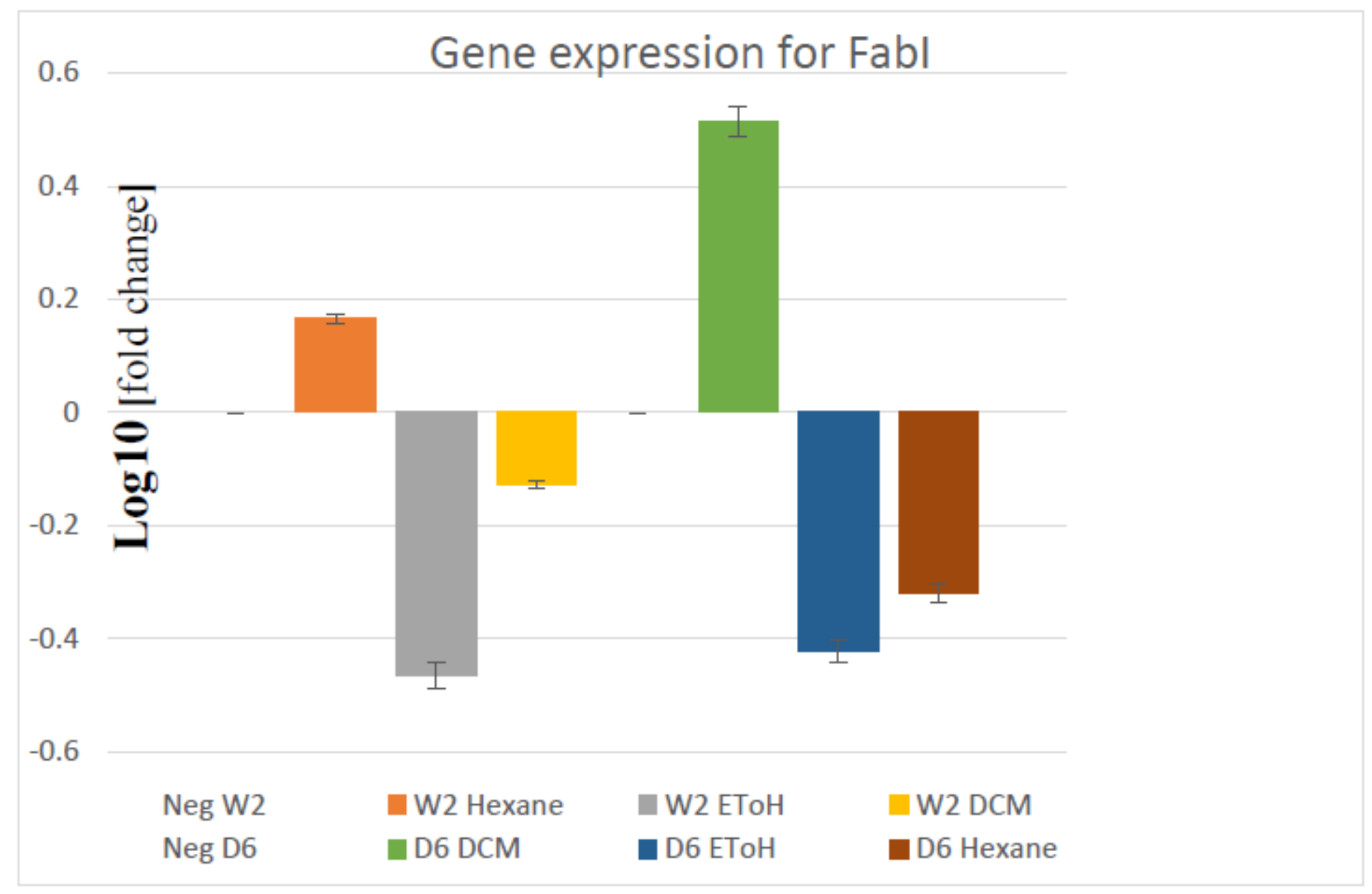

Figure 4

Gene expression for Fab I 


\section{Gene expression for FabZ}
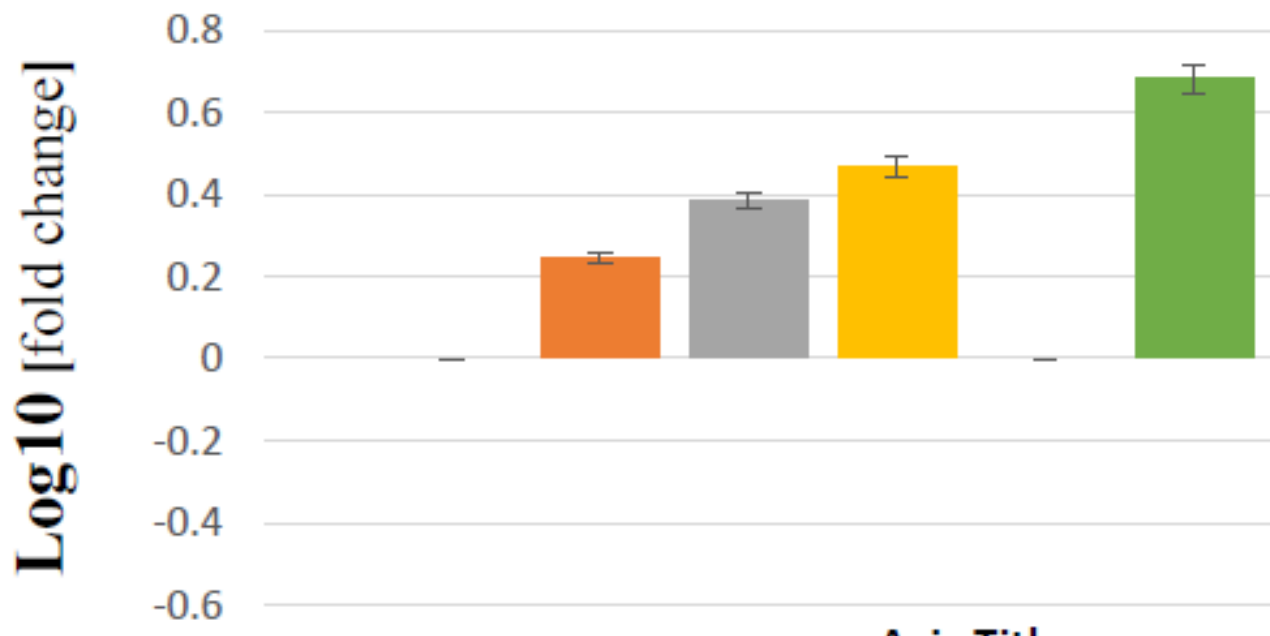

0.4

$-0.6$
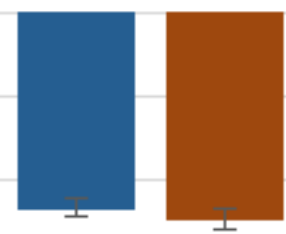

\section{Axis Title}

Neg W2 W2 Hexane $\square$ W2 EToH $\square$ W2 DCM

Neg D6 $\square$ D6 DCM $\square$ D6 EToH $\square$ D6 Hexane

Figure 5

Gene expression for Fab Z
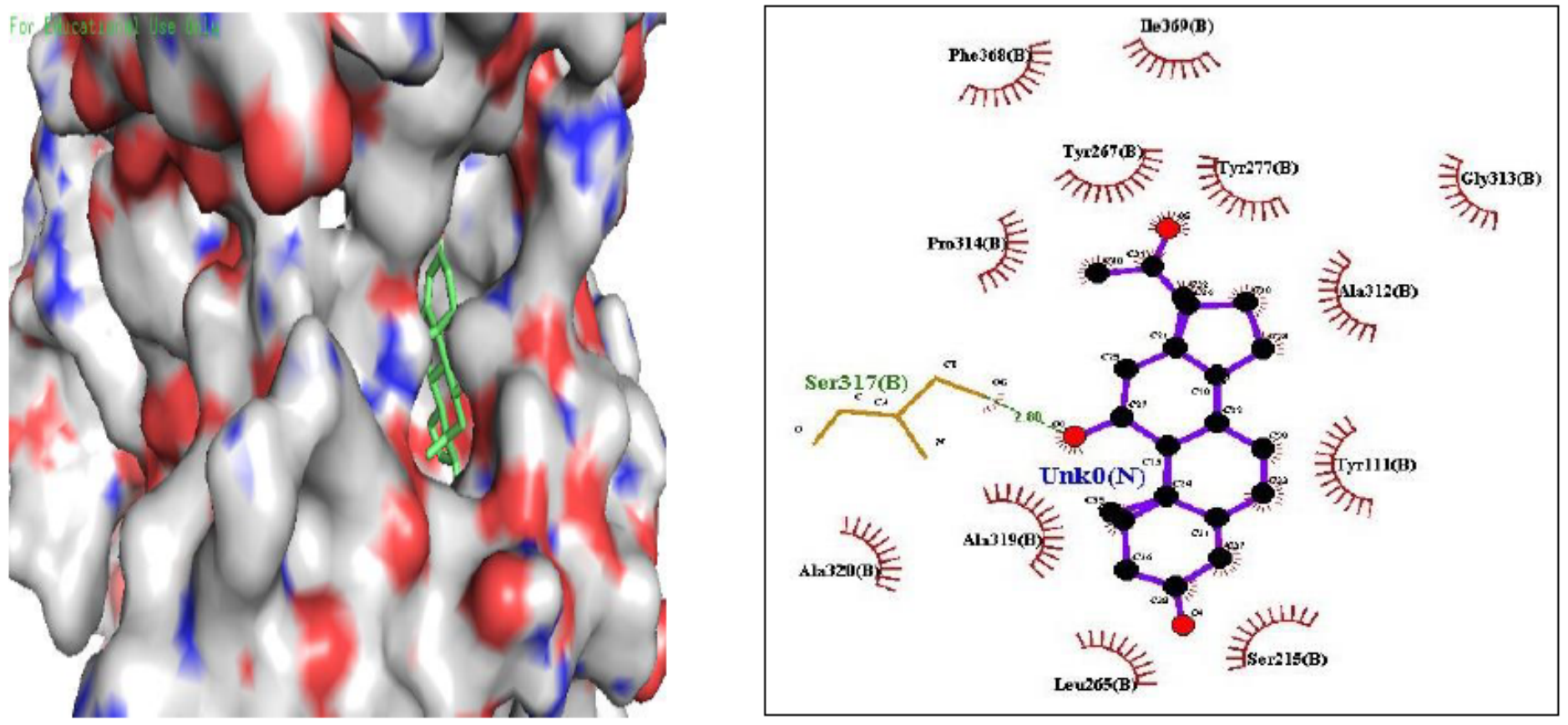

Figure 6

Interaction site for Fabl (chain B) and hit $\mathrm{N}^{\circ} 1$ (Hydroxyprogesterone) 


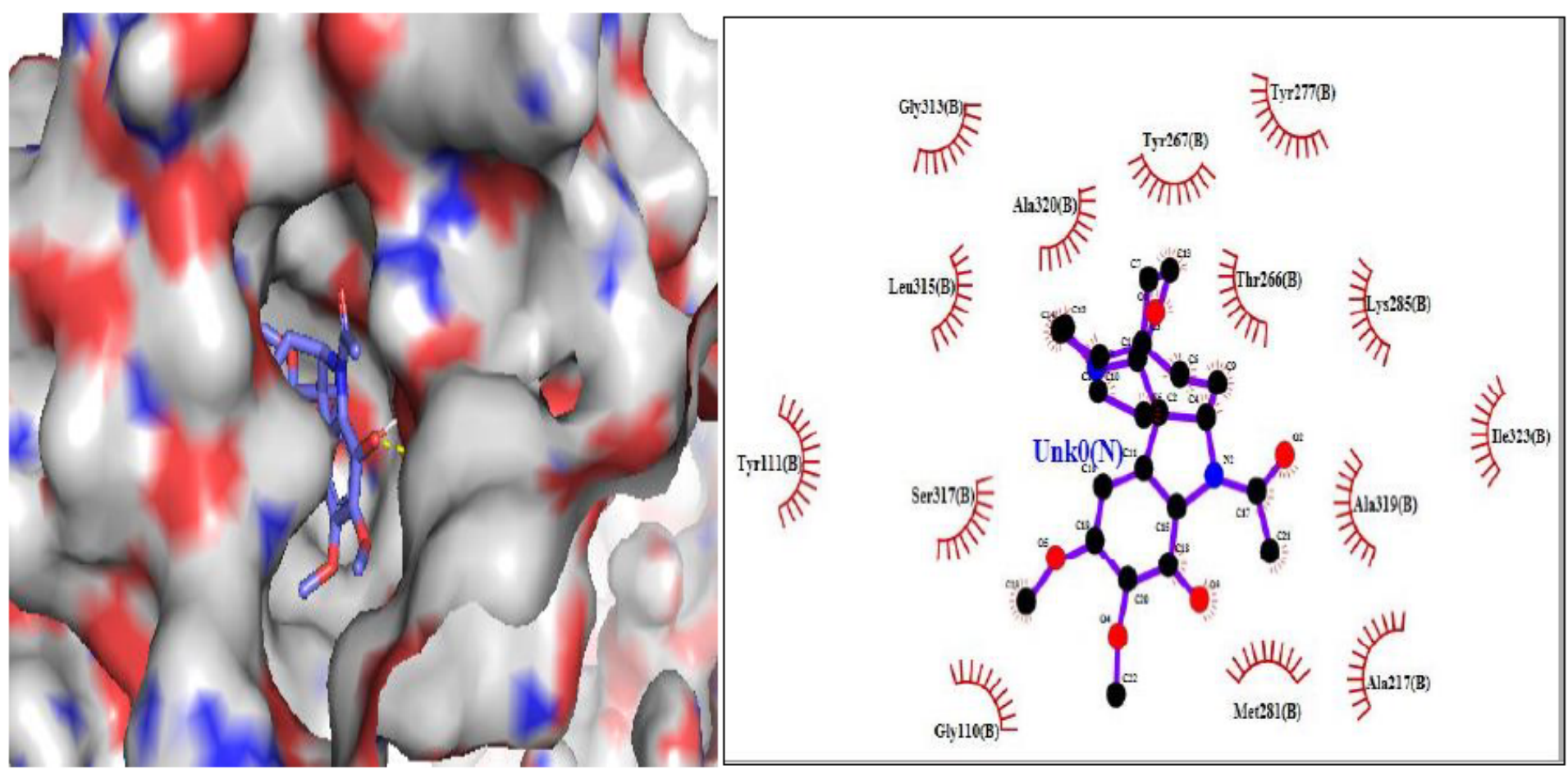

Figure 7

Interaction site for Fabl (chain B) and hit $\mathrm{N}^{\circ} 2$ (Aspidospermidin).
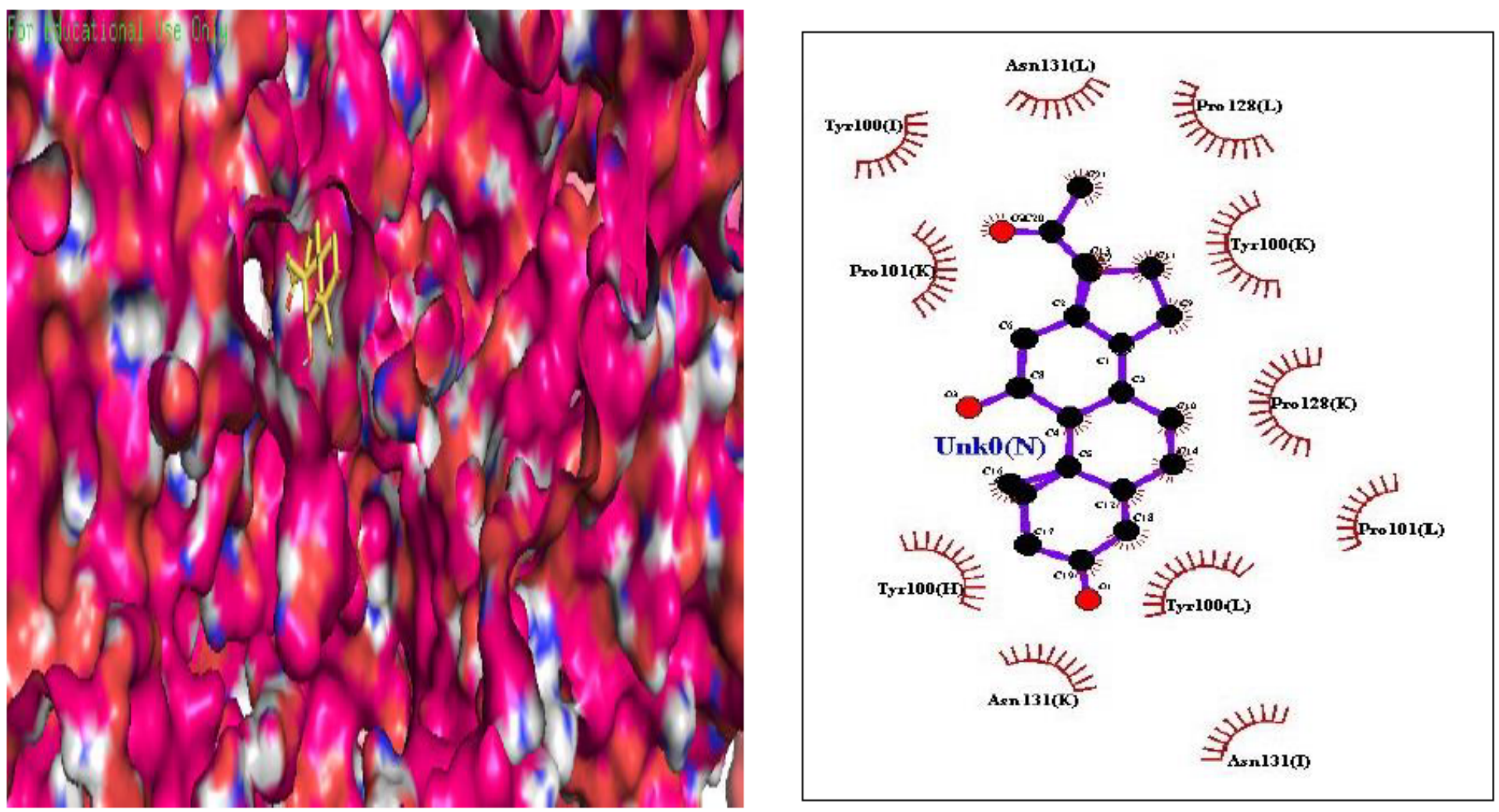

Figure 8

Interaction site for FabZ (chain $\mathrm{K}, \mathrm{L}, \mathrm{I}, \mathrm{H}$ ) and hit $\mathrm{N}^{\circ} 1$ (Hydroxyprogesterone). 

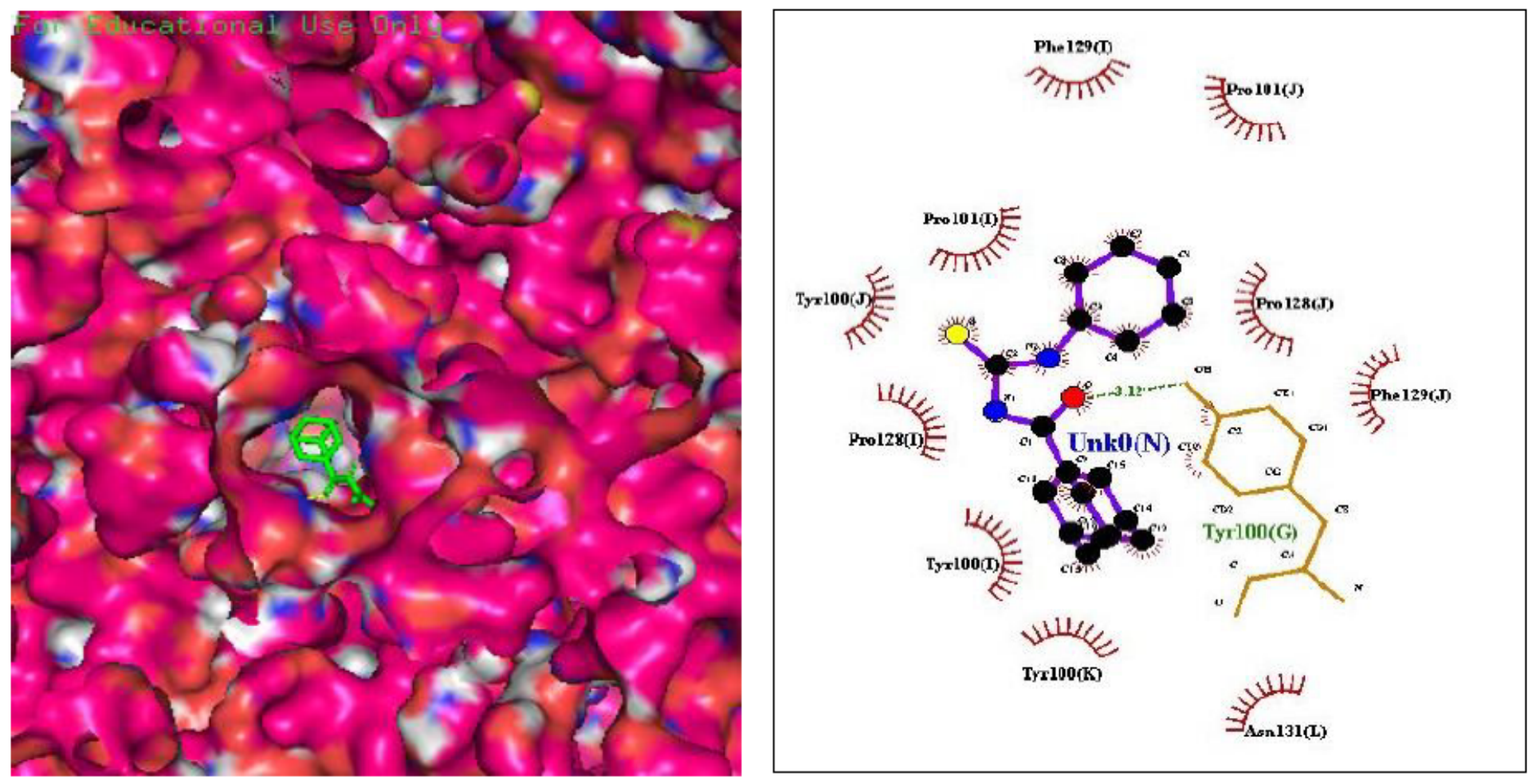

Figure 9

Interaction site for FabZ (chain $\mathrm{K}, \mathrm{L}, \mathrm{I}, \mathrm{J}, \mathrm{G}$ ) and hit $\mathrm{N}^{\circ} 2$ (Thiourea). 